Christoph M. Arndt, Robert Schieß1, Wolfgang Meier

OH Planar Laser-Induced Fluorescence Measurements with High Spatio-Temporal Resolution for the Study of Auto-Ignition

Applied Optics 58(10) (2019), C14-C22

This paper was published in Applied Optics and is made available as an electronic reprint with the permission of OSA. The paper can be found at the following URL on the OSA website:

https://www.osapublishing.org/ao/abstract.cfm?uri=ao-58-10-C14

(C) 2019 Optical Society of America, Inc. 


\title{
OH Planar Laser-Induced Fluorescence Measurements with High Spatio-Temporal Resolution for the Study of Auto-Ignition
}

\author{
Christoph M. ARndt, ${ }^{1,{ }^{*}}$ Robert Schießl ${ }^{2}$, Wolfgang Meier ${ }^{1}$ \\ ${ }^{I}$ German Aerospace Center (DLR), Institute of Combustion Technology, \\ Pfaffenwaldring 38-40, D-70569 Stuttgart, Germany \\ ${ }^{2}$ Karlsruhe Institute of Technology (KIT), Institute of Technical Thermodynamics, \\ Engelbert-Arnold-Str. 4, D-76131 Karlsruhe, Germany \\ *corresponding author: christoph.arndt@dlr.de
}

\begin{abstract}
For the detailed understanding of transient combustion processes, in particular, of auto-ignition, quantitative measurements with high spatio-temporal resolution are desirable. These can, for instance, serve as validation data for time-resolved numerical simulations, and, in particular for the combustion models used in those simulations. In the current study, a jet-in-hot-coflow (JHC) burner, developed at the German Aerospace Center (DLR), the DLR JHC, was used to inject a turbulent methane jet into the hot exhaust gas of a lean hydrogen/air fame, and a steady state jet flame was established." In addition, fuel could be injected in a transient manner. Here, an auto-igniting jet was observed. The flame stabilization of the steady state jet flame and the auto-ignition during transient fuel injection were studied using high-speed laser-based and optical measurements. A strategy for quantifying high-speed $\mathrm{OH}$ planar laser-induced fluorescence (PLIF) is presented and the measurement uncertainties are evaluated. The flame stabilization mechanism in steady state jet flames was assessed using probability density functions (PDFs) of the $\mathrm{OH}$ concentration at different axial and radial locations. The formation of auto-ignition kernels during transient fuel injection is evaluated based on time-series of the $\mathrm{OH}$ concentration. It is shown how the $\mathrm{OH}$ concentration levels and PDF shapes can be used to characterize the chemical state of the reacting flow and to distinguish between auto-ignition and flame propagation.
\end{abstract}

(C) 2019 Optical Society of America 


\section{Introduction}

For the development of modern gas turbine combustors, the detailed understanding of transient effects in reacting flows, for instance thermo-acoustic oscillations [1], lean blow-off [2], transitional flame states [3, 4] or auto-ignition [5] is of great importance. Auto-ignition can contribute to the flame stabilization in combustor systems with high recirculation rates, e.g. swirl $[6]$ or $\operatorname{FLOX}^{\circledR}[7,8]$ combustors, but has to be avoided in mixing sections of premixed combustors or Reheat combustor systems [9-11]. For the study of transient processes in complex systems, the (combined) application of time-resolved numerical simulations, such as large eddy simulations (LES), and optical measurement techniques with high spatio-temporal resolution within the same flow geometry is desirable. For the validation of numerical methods, quantitative data of experiments with wellknown and reproducible boundary conditions are needed. Therefore, a quantification of measurement signals from high-speed laser-diagnostics and the knowledge of the corresponding measurement uncertainties is desirable.

For the study of flame stabilization and auto-ignition in systems where (cold) fuel is injected into a hot, oxygen-containing environment, Jet-in-Hot-Coflow (JHC) burners provide an excellent configuration with welldefined and well-known boundary conditions [12-21]. The key issues that have been examined include the role of auto-ignition for the flame stabilization, the conditions at which auto-ignitions occur, the growth or extinction of igniting flame kernels, and the dependence of auto-ignition on temperature, fuel, mixture composition and flow velocities. Due to the ability of interference-free measurements, laser-based techniques have been the preferred choice for studying these issues.

Quantitative "low speed" species and temperature measurements have previously been performed in Jet-inHot-Coflow flames and are reported in the literature. For example, Cabra et al. [12] performed simultaneous Raman / Rayleigh / laser-induced fluorescence (LIF) measurements and used joint statistics of temperature vs. mixture fraction and $\mathrm{OH}$ mole fraction vs. mixture fraction to assess the thermo-chemical state of the flame. Gordon et al. [22] performed quantitative OH planar laser-induced fluorescence (PLIF) in combination with $\mathrm{CH}_{2} \mathrm{O}$ PLIF and planar Rayleigh scattering to study the stabilization mechanism of methane jets in a hot coflow. They found isolated ignition kernels upstream of the stably burning flame. Similarly, Medwell et al. [14] used $\mathrm{OH}$ PLIF and $\mathrm{CH}_{2} \mathrm{O}$ PLIF in combination with Rayleigh temperature imaging to assess the stabilization mechanism of natural gas [14] and ethylene [23] Jet-in-Hot-Coflow flames for different oxygen levels in the coflow. Oldenhof et al. performed coherent anti-Stokes Raman scattering (CARS) temperature measurements for the characterization of the temperature profiles of the coflow of the Delft JHC burner [17]. However, for a detailed understanding of the temporal development of transient processes, quantitative high-speed measurements are necessary $[19,20]$.

While quantitative high-speed measurements of flow fields with Particle Image Velocimetry (PIV) are state of the art [24, 25], quantitative results of scalars like mixture fraction, temperature, or species concentration are sparse in the literature [26-29]. So far, quantitative scalar measurements with high spatio-temporal resolution in Jet-in-Hot-Coflow flames are limited to temperature and mixture fraction. Arndt et al. and Papageorge et al. studied the formation of ignition kernels in a jet-in-hot-coflow (JHC) burner developed at the German Aerospace Center (DLR), the DLR JHC, using planar laser Rayleigh-scattering at a pulse repetition rate of $10 \mathrm{kHz}$ for different fuels [30-32]. It was found that the scalar dissipation rate plays a key role in determining the ignition time and location. However, for the validation of numerical simulations of transient combustion processes, further quantitative and time-resolved species data are desirable.

The goal of the current paper is to discuss an approach to quantitatively measure the concentration of the $\mathrm{OH}$ radical with high spatio-temporal resolution in an igniting methane jet in a vitiated coflow and assess the corresponding measurement uncertainties. Here, $\mathrm{OH}$ plays an important role as sensitive marker for auto-ignition and is a well suited quantity for comparing experimental and numerical results on auto-ignition. Probability density functions (PDFs) of the $\mathrm{OH}$ concentration were used to gain insight into the flame stabilization mechanism in stationary Jet-in-Hot-Coflow flames. For the study of the formation of ignition kernels, fuel was injected in a transient manner and the temporal development of initial auto-ignition kernels was assessed using radial profiles of the $\mathrm{OH}$ concentration at different time steps during the formation of an ignition kernel. Furthermore, unsteady numerical 1D-simulations in a counterflow geometry were performed to get additional insight into the combustion process and results from the experiments and simulations are compared. 


\section{Experimental Approach}

The formation of ignition kernels was studied in the DLR Jet-in-Hot-Coflow burner (DLR JHC) [19, 33]. Here, a turbulent cold fuel jet (methane) is injected into a hot laminar coflow of combustion products of a lean premixed hydrogen/air flat flame. This configuration allows the study of auto-ignition stabilized lifted jet flames and of the formation of ignition kernels.

A schematic of the DLR JHC is shown in Fig. 1a).

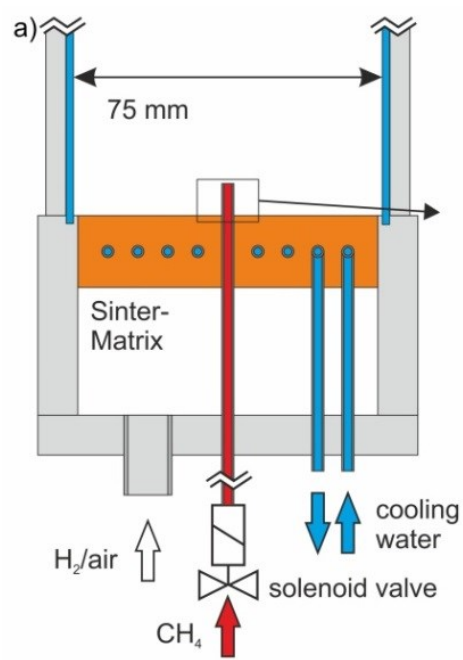

b)

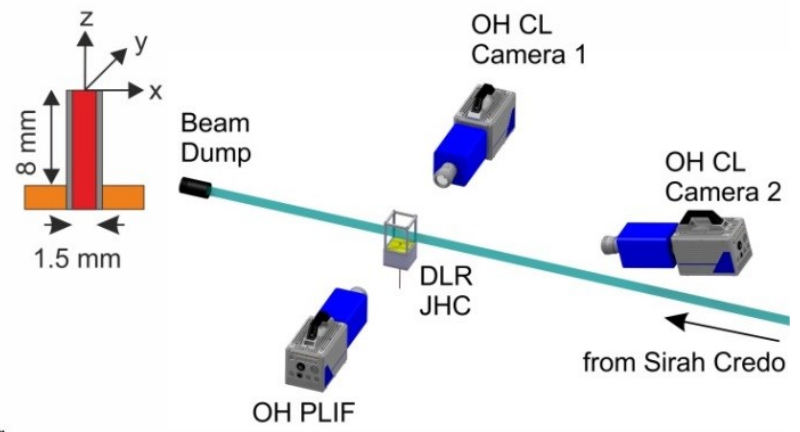

Fig. 1. Experimental setup. (a) DLR Jet-in-Hot-Coflow Burner (DLR JHC) (b) Optical and imaging setup.

The burner has been described in the literature in detail before [19, 31, 33], and only the key facts are discussed below.

The hot coflow was generated by a lean premixed hydrogen/air flat flame that was stabilized on a watercooled sintered bronze matrix with a cross section of $75 \times 75 \mathrm{~mm}^{2}$. The flame was confined by four quartz windows to prevent disturbance by ambient air. The nozzle was a stainless steel tube (inner diameter $\mathrm{D}=1.5 \mathrm{~mm}$ ), the tip of the nozzle was $8 \mathrm{~mm}$ above the matrix. Methane was either injected continuously for the study of lifted jet flames, or in a transient manner for the study of auto-ignition kernels. For the transient fuel injection, a 2/2 way solenoid valve (Staiger VA204-5), located approximately $250 \mathrm{~mm}$ (or $165 \mathrm{D}$ ) below the nozzle exit (to ensure fully developed pipe flow), was used. The operating condition for the jet and coflow presented in the current paper is summarized in Table 1.

Table 1. Operating conditions for the coflow for a coflow velocity of $4.1 \mathrm{~m} / \mathrm{s} . T_{a d}$ is the adiabatic flame temperature, $T_{c f}$ is the actual coflow temperature at $z=40 \mathrm{~mm}$ and $x=15 \mathrm{~mm}$, based on Rayleigh measurements [30, 31]. The coflow composition was calculated in the adiabatic equilibrium for a fresh gas temperature of $290 \mathrm{~K}$ using Gaseq [34]. $\xi_{s t}$ is the stoichiometric mixture fraction for the coflow-methane-mixtures.

\begin{tabular}{|c|c|c|c|c|c|c|c|c|c|c|}
\hline \multirow[b]{2}{*}{$\varphi_{c f}$} & \multicolumn{3}{|c|}{ Mass Flows $/ \mathrm{g} / \mathrm{min}$} & \multirow[b]{2}{*}{$T_{a d} / \mathrm{K}$} & \multirow[b]{2}{*}{$T_{c f} / \mathrm{K}$} & \multicolumn{4}{|c|}{ Coflow Composition } & \multirow[b]{2}{*}{$\xi_{s t}$} \\
\hline & $\dot{m}_{H_{2}}$ & $\dot{m}_{\text {air }}$ & $\dot{m}_{C H_{4}}$ & & & $X_{N_{2}}$ & $X_{\mathrm{H}_{2} \mathrm{O}}$ & $X_{O_{2}}$ & $X_{O H}$ & \\
\hline 0.465 & 3.86 & 285 & 12.5 & 1564 & 1490 & 0.7116 & 0.1778 & 0.1019 & $8.12 \times 10^{-5}$ & 0.0297 \\
\hline
\end{tabular}

The jet exit velocity was $182 \mathrm{~m} / \mathrm{s}$ and the jet Reynolds number (based on the fuel mass flow and the nozzle diameter) was 15,900 . During the transient fuel injection, the stagnation pressure in front of the solenoid valve was 0.8 bar between the fuel injections.

To study the formation of ignition kernels with high spatial and temporal resolution, a marker which is extremely sensitive to auto-ignition is needed. Therefore, planar laser-induced fluorescence (PLIF) of OH was imaged at a repetition rate of $10 \mathrm{kHz}$. A schematic of the experimental setup is shown in Fig. 1b).

A frequency doubled dye laser (Sirah Credo, pulse energy $0.1 \mathrm{~mJ}$ at $283.2 \mathrm{~nm}$, pulse duration $9 \mathrm{~ns}$ ) was pumped using a frequency-doubled Nd:YAG diode-pumped solid-state (DPSS) laser (EdgeWave InnoSlab IS8IIE, pulse energy $4 \mathrm{~mJ}$ at $532 \mathrm{~nm}$ ) and was tuned to match the $\mathrm{Q}_{1}(7)$ transition in the A-X $(1,0)$ band of the $\mathrm{OH}$ radical. The laser beam was formed into a light sheet using a cylindrical Galilean telescope and focused into the test section using a third cylindrical lens. The resulting sheet was $40 \mathrm{~mm}$ in height and had a beam waist of $0.4 \mathrm{~mm}$ in the test section. The fluorescence signal in the $(0,0)$ and $(1,1)$ bands was detected using an intensified high-speed CMOS camera (LaVision HSS8 with high-speed intensified relay optics (HS-IRO)) equipped with a fast UV lens (Cerco, $f=45 \mathrm{~mm}, \mathrm{f} / 1.8$ ) and a high transmission bandpass filter ( $\mathrm{T}>80 \%$ at $310 \mathrm{~nm}$, Laser Components). A short intensifier gate $(100 \mathrm{~ns})$ was used to suppress background luminosity of the flame. Two additional high-speed intensified CMOS cameras were used to image $\mathrm{OH}^{*}$ chemiluminescence (CL) from two viewing angles in order to reconstruct the location of ignition kernels in the three-dimensional space. For the 
evaluation of the planar measurements, only ignition kernels that formed within the laser light sheet were evaluated. For the steady state condition, image series of $>7,500$ image frames were recorded. For the transient auto-ignition cases, 225 individual auto-ignition events, each consisting of 100 image frames, were recorded.

The basic principle of the quantification of the OH PLIF signal in the current experiment is based on the knowledge of the $\mathrm{OH}$ concentration within the coflow. Using the relation between $\mathrm{OH}$ LIF signal and $\mathrm{OH}$ concentration in the coflow, the $\mathrm{OH}$ LIF signals in reacting regions can be quantitatively determined if quantities such as quenching and temperature-dependent factors are taken into consideration (see below). Since the coflow temperature is well known from Rayleigh measurements, the $\mathrm{OH}$ concentration in the coflow can be determined using equilibrium calculations. Fig. 2 shows the average OH PLIF distribution for a steady state lifted jet flame surrounded by the coflow flame that was operated at $\phi_{c f}=0.465$ and $T_{c f}=1490 \mathrm{~K}$.

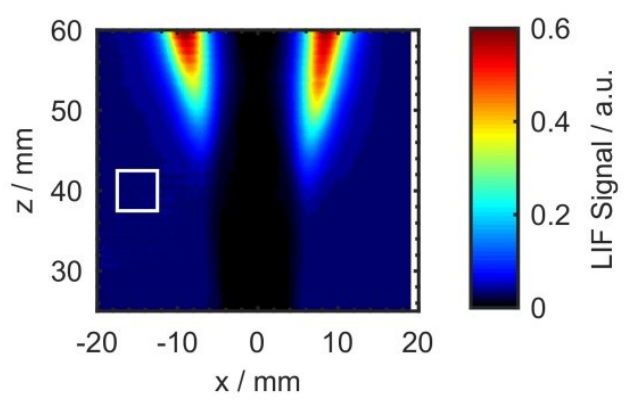

Fig. 2. Average OH PLIF signal from a steady state lifted jet flame surrounded by the coflow flame with $\phi_{c f}=0.465$. The white square marks the region in which the coflow temperature was measured using laser Rayleigh scattering and in which the calibration for the OH PLIF signal was performed.

The $\mathrm{OH}$ in the coflow can be seen as faint blue signal left and right of the inflowing, cold methane jet (black). The high signal intensity in the shear layer of the jet corresponds to the lifted jet flame. The white rectangle marks the region, in which the $\mathrm{OH}$ concentration in the laminar coflow was calibrated using the coflow temperature. Fig. 3a) shows the probability density function (PDF) of the coflow temperature based on the temperature distribution in the marked region $(\mathrm{x}=-15 \pm 2.5 \mathrm{~mm}, \mathrm{z}=40 \pm 2.5 \mathrm{~mm})$.
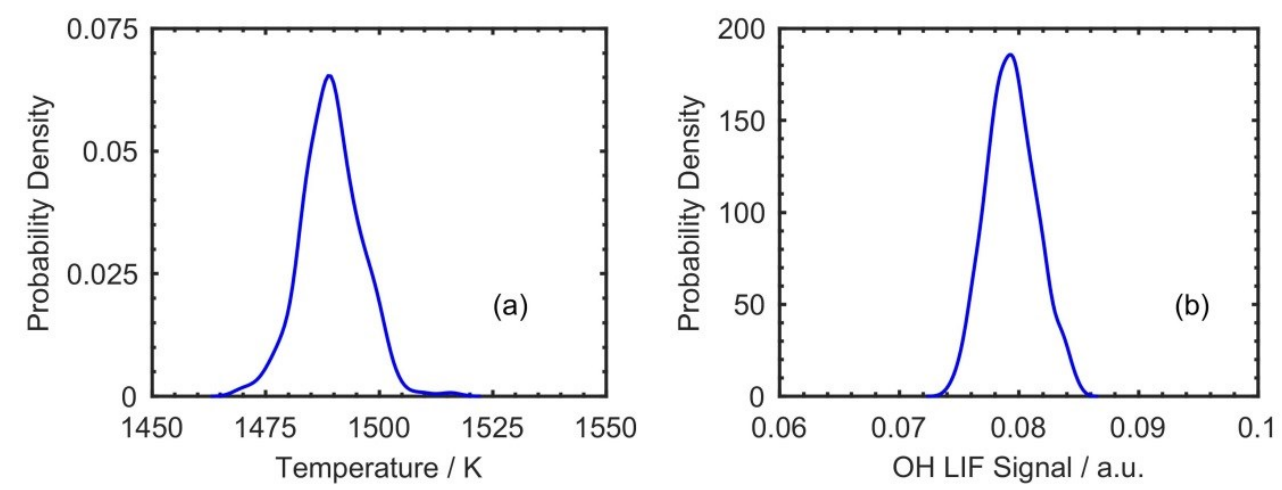

Fig. 3. Probability Density Function of (a) the coflow temperature and (b) the OH PLIF signal in the region indicated in Fig. $2(\mathrm{x}=-15 \pm 2.5 \mathrm{~mm} \mathrm{y}=40 \pm 2.5 \mathrm{~mm})$.

Both the most probable and the mean temperature of the coflow in this region are $1489 \mathrm{~K}$ with a standard deviation of $6.5 \mathrm{~K}$ or $0.4 \%$. Fig. $3 \mathrm{~b}$ ) shows the PDF of the normalized PLIF signal (with respect to the maximum signal in the image frame) for the same region as the temperature PDF. Here, the mean signal is 0.0794 and the standard deviation of the signal is 0.0021 or $2.6 \%$. Based on the averaged distribution (which is used for calibration the $\mathrm{OH}$ signal), the signal-to-noise ratio in the coflow is approximately 37 . On a single-pixel basis, the signal-to-noise ratio in the coflow region is approximately 10, and within the reaction zone it is approximately 75. The quantification of the PLIF signal is a multi-step process, which is described in the next section. 


\section{Data Reduction and Analysis}

Besides other effects that are discussed below, the measurement signal is affected by signal trapping [35, 36] from both $\mathrm{OH}$ in the reaction zone and $\mathrm{OH}$ that exists in the coflow in an equilibrium concentration. Since the distribution of $\mathrm{OH}$ in the coflow is homogeneous, signal absorption by the coflow is also considered to be constant throughout the image frame. Due to the reaction zone being rather thin, and the homogeneous signal absorption within the coflow, effects of signal absorption are neglected in the current study. Furthermore, laserenergy is absorbed by $\mathrm{OH}$ within the test section, resulting in locally lower laser energy at the laser exit side of the test section in comparison to the laser entry side. Since the $\mathrm{OH}$ concentration in the coflow region is low and the reaction zones are rather thin, the amount of laser-energy absorbed within the test section is low and was measured to be on the order of $5 \%$. This translates directly to a measurement uncertainty on the same order due to unknown local laser intensity. Since all further data evaluations were carried out on the laser entry side of the test section, the resulting measurement uncertainty is even lower than $5 \%$.

\subsection{Image Processing}

To quantify the $\mathrm{OH}$ concentration in the measurement volume, several calibration steps have to be performed. After darkfield and whitefield correction, a 3x3 pixel software binning was applied to improve the signal to noise ratio. After binning, the in-plane spatial resolution was $0.13 \mathrm{~mm} /$ pixel. The background was determined using a 10 pixel wide column in the region of the cold methane jet, where no $\mathrm{OH}$ is present. Non-uniformities in the laser sheet were corrected by imaging the fluorescence of a homogenous distribution of acetone vapor inside the combustion chamber. Shot-to-shot intensity fluctuations of the laser and the calibration to an absolute $\mathrm{OH}$ concentration were performed using an area of the coflow with known temperature and composition. The equilibrium $\mathrm{OH}$ concentration however is very sensitive to the local temperature, as shown in Fig. 4.

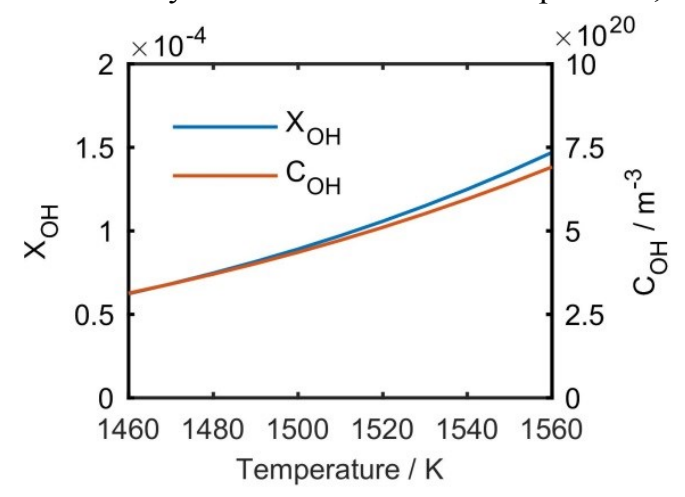

Fig. 4. Temperature dependence of the $\mathrm{OH}$ mole fraction (blue) and the $\mathrm{OH}$ concentration (red) for a hydrogen/air flame with $\phi=0.465$ (calculated with GasEQ [34]).

Within the uncertainty of the Rayleigh temperature measurements $(<2 \%)$, the $\mathrm{OH}$ concentration within the coflow varies by approximately $25 \%$.

\subsection{LIF Signal Quantification and Measurement Uncertainties}

The local LIF signal intensity can be described as follows [37]:

$S_{L I F}=B \cdot I_{L} \cdot \Gamma \cdot \tau_{L} \cdot N \cdot f_{B} \cdot \Phi \cdot F_{f l} \cdot(\Omega / 4 \pi) \cdot \epsilon \cdot \eta \cdot V$

Here, $B$ is the Einstein absorption coefficient divided by the speed of light, $I_{L}$ is the laser spectral power density per unite area, divided by the laser bandwidth, $\Gamma$ is a linewidth integral reflecting the overlap between laser and absorption line spectral profiles and $\tau_{L}$ is the laser pulse length. Since in the current study, a part of the measurement volume with a known $\mathrm{OH}$ concentration is used as a calibration source, these quantities do not have to be determined. For a description of the remaining quantities in Eq. (1) see the following paragraphs.

The number of molecules in the electronic ground state $N$ is the actual quantity that is to be measured. Here, the Boltzmann-fraction $f_{B}$ which is the portion of the molecules in the particular electronic-vibrational-rotational level being excited by the laser has to be considered, since it depends on the local temperature. The temperature dependence of the Boltzmann population in the ground state for the $\mathrm{X}$-state $\left(v^{\prime \prime}=0, \mathrm{~J}^{\prime \prime}=7.5, \mathrm{~J}=\mathrm{K}+1 / 2\right)$,) is shown in Fig. 5a). 

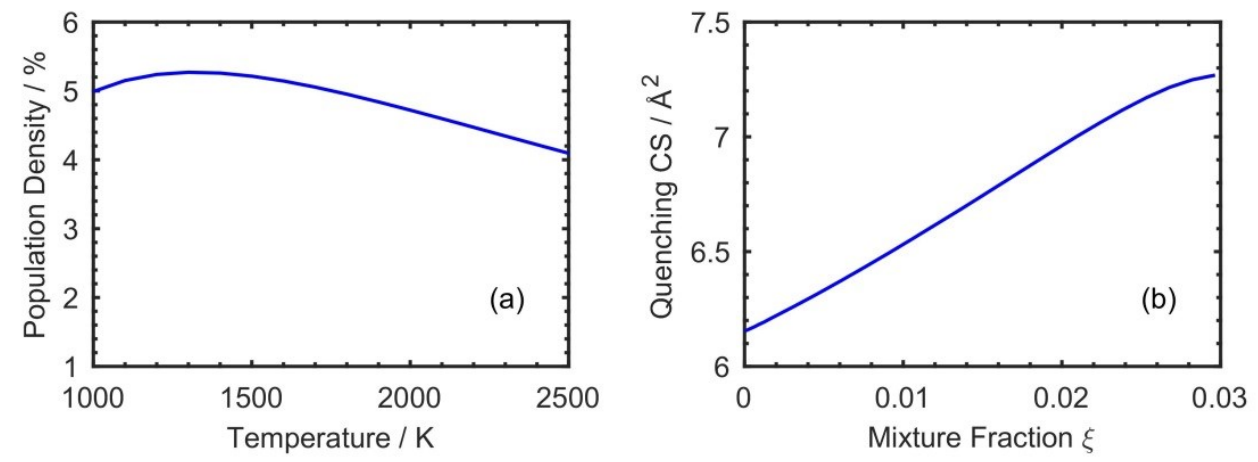

Fig. 5. (a) temperature dependence of the population density in the $X$-state ( ${ }^{\prime \prime} "=0, J$ ' $\left.=7,5, J=K+1 / 2\right)$ (calculated with LIFBASE [38]). (b) calculated quenching cross section in dependence of the mixture fraction (using data from [39]).

Within the temperature range of interest for the current study $\left(T_{c f}<T<T_{a d, \max }\right)$, namely between $1500 \mathrm{~K}$ and $2300 \mathrm{~K}$, the population density changes by approximately $20 \%$, thus leading to an underestimation of the $\mathrm{OH}$ concentration due to the unknown local Boltzmann-fraction.

$\Phi$ is the fluorescence quantum yield from the excited state, i.e. the number of photons emitted per molecule excited. This is a key quantity that is affected by collisions and dissociation. Thus, the local effective quenching cross section has to be taken into account.

Fig. 5b) shows the modelled effective fluorescence quenching cross section in dependence of the mixture fraction. Here, the mixture fraction was defined as the mass fraction of the fuel $\left(\mathrm{CH}_{4}\right)$ in the considered volume. In the graph, the local mixture composition corresponds to the adiabatic equilibrium after complete reactions. Since reactions are expected to occur either at very lean mixtures (for auto-ignition) or close to the stoichiometric mixture fraction (in the case of flame propagation), only mixture fractions smaller or equal to the stoichiometric mixture fraction are considered here. The quenching cross section for $\xi=0$ corresponds to pure coflow fluid, i.e. the area where the measurement signal is calibrated. The quenching cross section increases with increasing mixture fraction, which is mainly due to the large quenching cross sections of water and carbon dioxide, which are formed during flame reactions. Across the reaction zone, the quenching cross section varies by approximately $20 \%$. Since the local composition (or $\xi$ ), was not measured simultaneously with the $\mathrm{OH}$ concentration, this corresponds to a measurement uncertainty which cannot be corrected.

The remaining quantities in Eq. (1) are characteristics of the detector and detection optics, namely the fraction of fluorescence collected within the detector bandwidth $F_{f l}$, the solid angle of fluorescence collected by the detector $\Omega$, the transmission and photoelectron efficiencies of the detector system $\epsilon$ and $\eta$ and the observed interaction volume $V$. Again, since a part of the measurement volume is used as a calibration source, these quantities do not have to be considered separately in the calibration procedure.

The total measurement uncertainty is $\pm 25 \%$ in the coflow region and $+60 \% /-25 \%$ in the reaction zone. This has to be considered for model validation. Alternatively, the LIF-signal can be simulated directly with numerical models. Here, using the $\mathrm{OH}$ concentration in the coflow for shot-to-shot laser intensity corrections increases the quality of the presented data set as well. 


\section{Results and Discussion}

\subsection{Flame Stabilization in Steady State Flames}

First, the flame stabilization in steady state lifted jet flames is examined. Fig. 6 shows the mean and standard deviation of the calibrated OH PLIF images as well as a representative single shot.
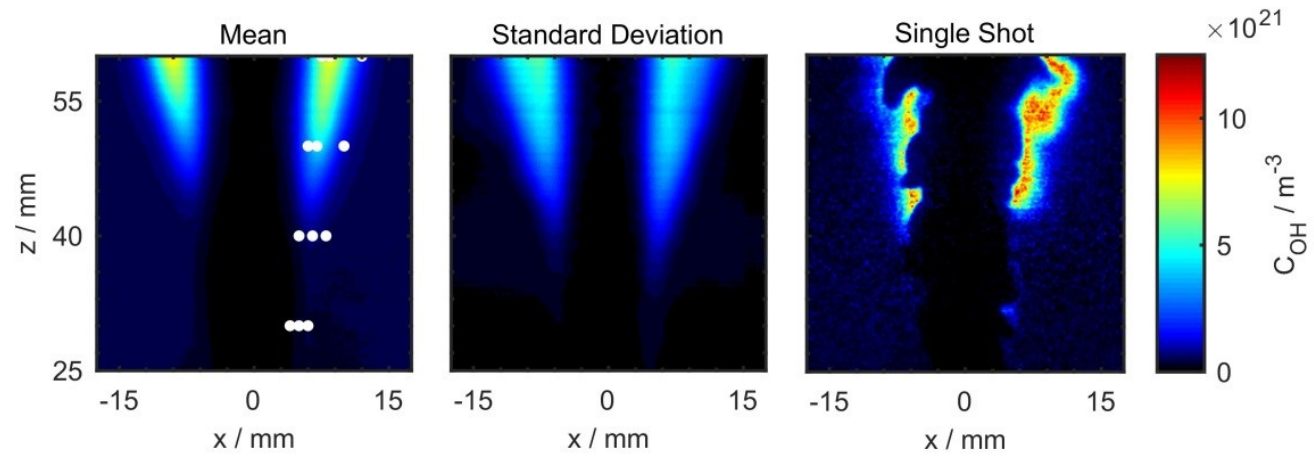

Fig. 6. Representative OH PLIF measurement: mean, standard deviation and single shot. The closed symbols correspond to the locations where the PDFs of the $\mathrm{OH}$ concentration (cf. Fig. 7) were evaluated.

The color bar corresponds to the $\mathrm{OH}$ concentration $\left(\right.$ in $\mathrm{m}^{-3}$ ). The white closed symbols correspond to the locations where probability density functions ( $\mathrm{PDFs}$ ) of the $\mathrm{OH}$ concentration were evaluated (see below). The mean $\mathrm{OH}$ image shows a lifted jet flame, with the flame root being approximately $40 \mathrm{~mm}$ above of the fuel nozzle. Downstream of the flame root, the $\mathrm{OH}$ concentration within the reaction zone increases continuously. Variances of the $\mathrm{OH}$ concentration are present upstream of the apparent flame root, which is a first indication of the formation of auto-ignition kernels below the flame root. Within the single shot shown in Fig. 6, an increased $\mathrm{OH}$ concentration can be seen at approximately $\mathrm{z}=30 \mathrm{~mm}$ and $\mathrm{x}=5 \mathrm{~mm}$, which also could be indicative for auto-ignition. Here, $\mathrm{OH}^{*} \mathrm{CL}$ from two viewing angles (as describe in Section 2) can be used to distinguish between ignition kernel forming within the laser light sheet and out-of-plane effects.

In order to further assess the flame stabilization mechanism, $\mathrm{PDFs}$ of the $\mathrm{OH}$ concentration were calculated at different axial and radial locations. The corresponding locations are visualized by white close symbols in Fig. 6 and the calculated PDFs are shown in Fig. 7. 

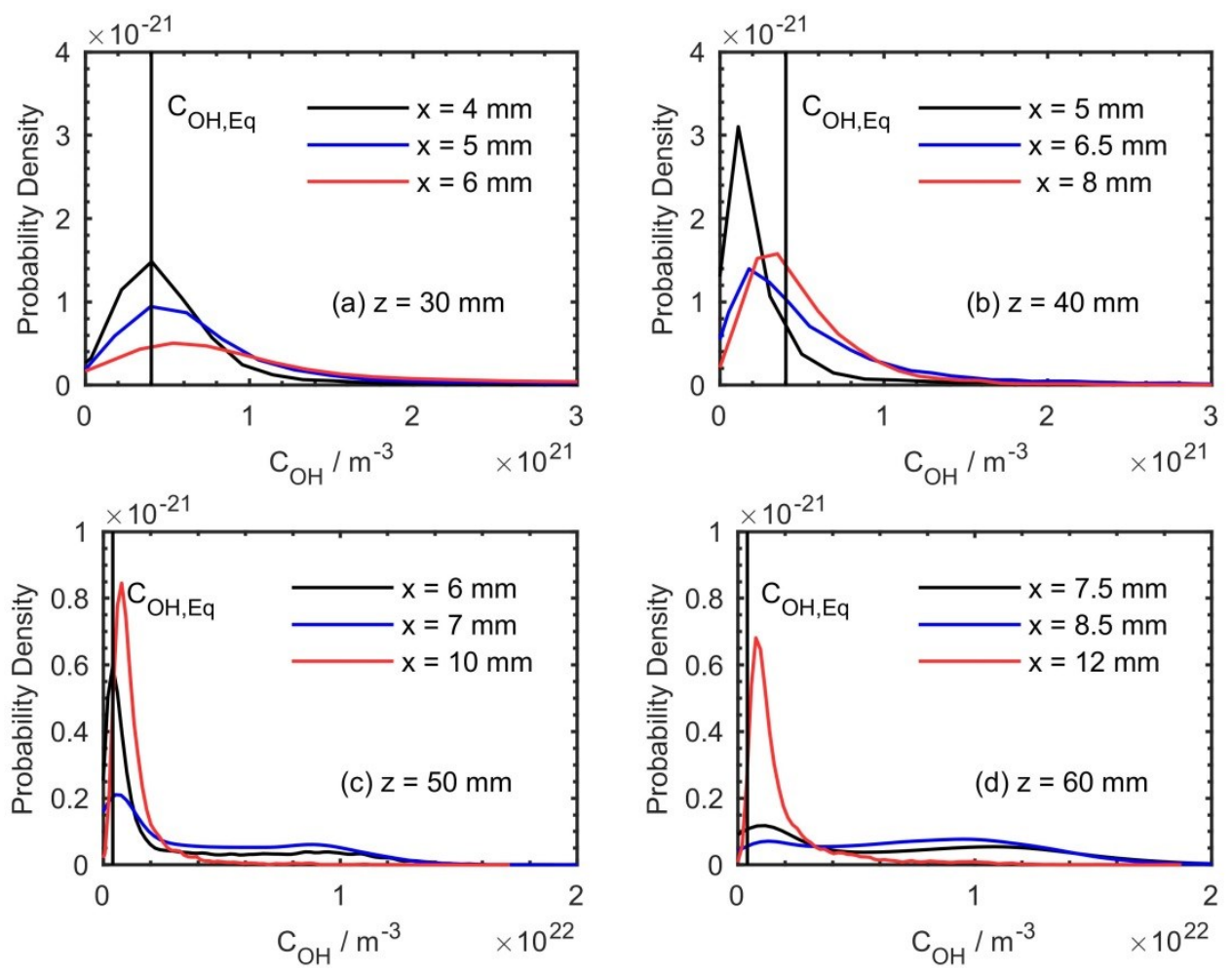

Fig. 7. Probability Density Functions (PDFs) of the $\mathrm{OH}$ concentration at different axial and radial positions.

The black curves correspond to the shear layer (radial position of the maximum of the standard deviation of the $\mathrm{OH}$ concentration), the blue curves correspond to the main reaction zone (radial position of the maximum of the $\mathrm{OH}$ concentration) and the red curves are at the transition from the reaction region to the coflow (radial position were the mean $\mathrm{OH}$ concentration decreases to the equilibrium value within the coflow). The black vertical line indicates the $\mathrm{OH}$ equilibrium concentration in the coflow. $\mathrm{OH}$ concentrations significantly larger than $C_{O H, E q}$ indicate chemical reactions of fuel from the jet with $\mathrm{O}_{2}$ from the coflow. OH concentrations significantly smaller than $C_{O H, E q}$ can be interpreted as mixtures of coflow and jet fluid which have not reacted yet $\left(T<T_{c f}\right)$ or as fuel-rich mixtures $\left(\xi>\xi_{\text {stoich }}\right)$. At $\mathrm{z}=30 \mathrm{~mm}$ and $\mathrm{z}=40 \mathrm{~mm}$, the $\mathrm{OH}$ concentration is broadly distributed around the equilibrium concentration of the coflow. The tail of the PDF towards higher $\mathrm{OH}$ concentrations is indicative for regions where auto-ignition occurs. In configurations where cold fuel is mixed with a hot oxidizer stream, the mixture fraction at which auto-ignition occurs is typically very lean, due to the high mixture temperatures and strong dependence of auto-ignition on the local temperature [5]. Hence, autoignition leads to a continuous increase of the $\mathrm{OH}$ concentration in regions with very lean mixture fractions (i.e. regions that are dominated by the coflow fluid). This behavior leads to a broadening of the OH PDFs, as is apparent at $\mathrm{z}=30 \mathrm{~mm}$ and $\mathrm{z}=40 \mathrm{~mm}$.

In contrast, at $\mathrm{z}=50 \mathrm{~mm}$ and $\mathrm{z}=60 \mathrm{~mm}$, the distribution of the $\mathrm{OH}$ concentration becomes increasingly bimodal. This is indicative for the flame stabilization mechanism switching from auto-ignition to flame propagation. Due to the highest flame velocities occurring close to the stoichiometric mixture fraction, a diffusion flame will stabilize in this region [40]. Hence, the $\mathrm{OH}$ distribution features a second peak, which corresponds to the $\mathrm{OH}$ concentration in near-stoichiometric, reacting regions, and the $\mathrm{OH}$ distribution becomes more bimodal, as evident at $\mathrm{z}=50 \mathrm{~mm}$ and $\mathrm{z}=60 \mathrm{~mm}$. For stoichiometric, reacting regions, the $\mathrm{OH}$ concentration and adiabatic flame temperature (based on equilibrium calculations [34]) are $\mathrm{C}_{\mathrm{OH}}=2.1 \times 10^{22} \mathrm{~m}^{-3}$ and $\mathrm{T}_{\mathrm{ad}}=2285 \mathrm{~K}$, under strained conditions, the $\mathrm{OH}$ concentration is expected to be even higher [41]. The additional peak in the PDFs in Fig. 7 is centered at approximately $\mathrm{C}_{\mathrm{OH}}=1 \times 10^{22} \mathrm{~m}^{-3}$. Considering the underestimation of the $\mathrm{OH}$ concentration in stoichiometric, reacting regions of approximately $60 \%$ in the current measurement, as discussed in Section 3.2, this supports the assumption of the flame stabilizing at nearstoichiometric mixture fraction.

\subsection{Transient Development of Auto-Ignition Kernels}

In configurations where cold fuel mixes with a hot oxidizer, auto-ignition occurs at the so-called most reactive mixture fraction $\xi_{m r}$, where the chemical kinetic ignition delay time is shortest. Due to the highest mixture temperatures occurring at very lean mixtures, the most reactive mixture fraction is typically very lean. For the here studied configuration, it is on the order of $1 \%$ of the stoichiometric mixture fraction [33]. Additionally, the 
scalar dissipation rate has a strong influence on auto-ignition, i.e. auto-ignition occurs at locations along the isosurface of $\xi_{m r}$, where the scalar dissipation rate is minimal. Fig. 8 shows an image sequence of the formation of an ignition kernel. Color coded is the $\mathrm{OH}$ concentration $\mathrm{C}_{\mathrm{OH}}$.

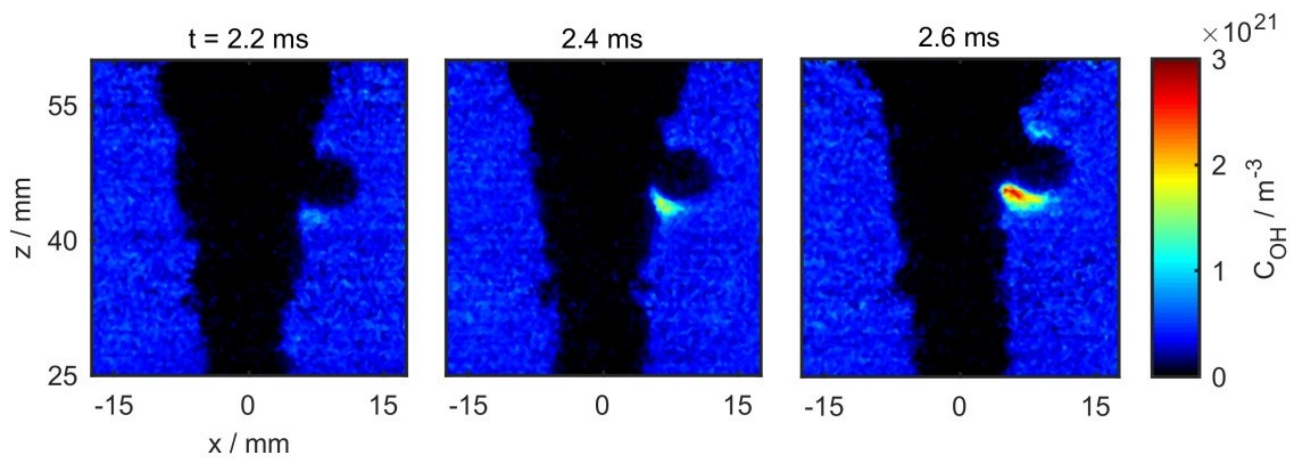

Fig. 8. Development of the $\mathrm{OH}$ concentration during the formation of an ignition kernel.

The dark region in the center of the image corresponds to the inflowing cold methane jet, the light blue regions left and right of the fuel jet correspond to the equilibrium $\mathrm{OH}$ concentration in the coflow. For a space-saving presentation, only every second image frame is shown. At $t=2.2 \mathrm{~ms}$, an ignition kernel forms upstream of a bulge of the inflowing jet. In previous studies, it has been shown that the scalar dissipation rate is minimal at concave interfaces between the fuel and the hot oxidizer [19, 31, 42]. The kernel grows with time, and $\mathrm{C}_{\mathrm{OH}}$ rises. To better assess the formation and subsequent growth of ignition, radial profiles of the $\mathrm{OH}$ concentration at the axial location of the ignition kernel were extracted from the 2D distributions (axially averaged over a range of 5 pixels or $0.65 \mathrm{~mm}$ ) and their temporal development is displayed in Fig. 9.

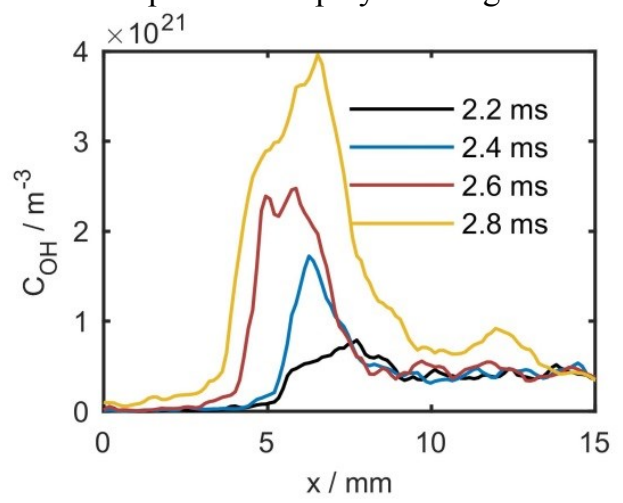

Fig. 9. Temporal development of the radial profile of the $\mathrm{OH}$ concentration during the formation of an ignition kernel.

Similar to the 2D images of the $\mathrm{OH}$ concentration, the radial profiles show the formation of the ignition kernel at $\mathrm{t}=2.2 \mathrm{~ms}$, as visualized by a slight increase of the $\mathrm{OH}$ concentration above its equilibrium concentration in the coflow. As discussed above, in configurations with cold fuel and hot oxidizer, auto-ignition typically occurs at very lean mixture fractions (i.e. close to the coflow, away from the jet core) due to the highest mixture temperatures occurring there. After the formation of the ignition kernel, the $\mathrm{OH}$ concentration increases rapidly due to the reaction progress and the maximum of the $\mathrm{OH}$ concentration profile shifts to smaller radii (i.e. closer to the jet core) with time. This corresponds to an expansion from very lean to richer mixtures, as measurements of the mixture fraction [31] showed. Since the highest flame speed occurs close to the stoichiometric mixture fraction, the flame kernel expands towards the stoichiometric mixture fraction after its initial formation. This is in agreement with the observed shift of the maximum $\mathrm{OH}$ concentration closer to the jet core with time. The behavior observed here is typical for the formation of ignition kernels in the DLR JHC [33]. The profiles shown in Fig. 9 do not cover the complete temporal development of the ignition kernel for clarity reasons. Since the spatio-temporal development of the ignition kernel is also superimposed by turbulent motion of the surrounding flow, the peak of the $\mathrm{OH}$ concentration at $\mathrm{t}=2.8 \mathrm{~ms}$ is slightly shifted towards the coflow region, and thus interpretations of the location of the maximum $\mathrm{OH}$ concentration for this and following time instances might not be accurate. After complete development of the ignition kernel, $\mathrm{OH}$ concentrations similar to those in the steadystate jet flame (cf. Fig. 6) are expected, which are on the order of $10^{22} \mathrm{~m}^{-3}$.

To gain a deeper insight into the process of ignition kernel formation and ignition kernel growth in strained flows, numerical model simulations using the unsteady flame code INSFLA [43] have been performed for a counterflow arrangement. This code numerically solves the Navier-Stokes equations for an one-dimensional counterflow geometry, including full spatial resolution by an auto-adaptive dynamic spatial grid, and a built-in error control for time-stepping. It treats chemical reaction and its interaction with molecular transport processes 
in detail. The simulations were performed with boundary conditions set to values very similar to the current experiment. Here, one of the two flows corresponds to pure fuel at $\mathrm{T}_{\mathrm{CH} 4}=300 \mathrm{~K}$ and the other flow corresponds to the hot exhaust gas of a lean premixed hydrogen air flame with an equivalence ratio of $\varphi=0.485$. Details of the numerical setup can be found in [33]. Although the conditions are slightly different (due to the slightly higher oxidizer temperature in comparison to the experiment), the observed trends are expected to be the same. Fig. 10 shows the temporal development of the $\mathrm{OH}$ concentration in the mixture fraction space derived from the simulations.

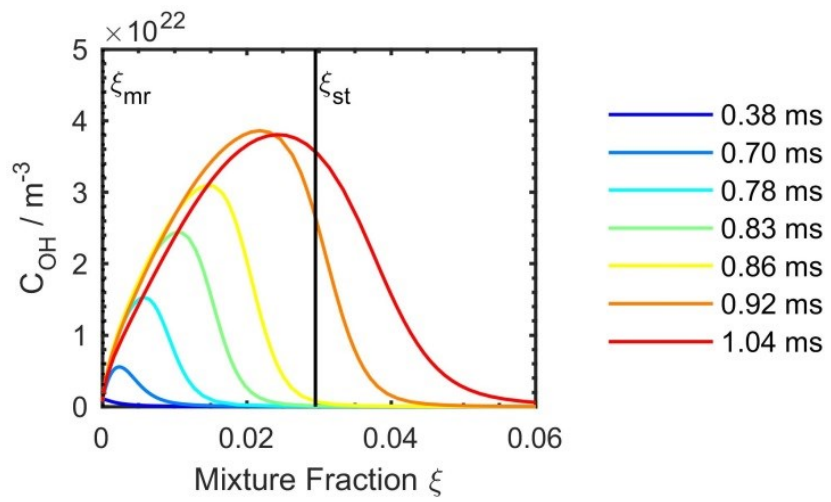

Fig. 10. Calculated temporal development of the $\mathrm{OH}$ concentration for a coflow temperature $\mathrm{T}_{\mathrm{cf}}=1607 \mathrm{~K}$, coflow equivalence ratio $\phi_{\mathrm{cf}}=0.485$ and strain rate of $701 / \mathrm{s}$. The vertical lines correspond to the most reactive mixture fraction $\xi_{\mathrm{mr}}=6.6 \times 10^{-5}$ (very close to the ordinate) and to the stoichiometric mixture fraction $\xi_{\mathrm{st}}=0.0295$, respectively.

The initial formation of the ignition kernel is at the most reactive mixture fraction, which was determined to be $\xi_{\mathrm{mr}}=6.6 \times 10^{-5}$ for the conditions examined here. This small value is mainly due to the fact that the temperature at small mixture fractions is very high, which favors fast initial chemical reactions at these conditions. Subsequently, the kernel grows (indicated by the rise of the $\mathrm{OH}$ concentration) and expands towards stoichiometric mixtures (visible by the shift of the peak of the $\mathrm{OH}$ concentration towards the stoichiometric mixture fraction). Near the stoichiometric mixture fraction, the flame propagation velocity is highest, and thus a flame is expected to stabilize here. The observations from the simulations match the observations from the experiment: in both cases, the ignition kernel forms at very lean mixture fractions and subsequently grows into areas with near-stoichiometric mixture fraction. Also, the time between the formation of the kernel and the occurrence of the maximum $\mathrm{OH}$ concentration is on the order of 1 millisecond in both the experiment and the simulation. Therefore, despite the simple geometry of the simulations (1D versus the 3D geometry of the real jet), they capture some essential aspects of the auto-ignition and flame propagation process well. However, as simplified representation of the experiment, the simulations are not expected to cover all effects occurring in the real flame.

\section{Summary and Conclusions}

Quantitative $\mathrm{OH}$ planar laser-induced fluorescence measurements with high spatio-temporal resolution ("High Speed OH PLIF") have been performed to study auto-ignition in the DLR Jet-in-Hot-Coflow burner (DLR JHC). Since the temperature boundary conditions in the DLR JHC are well-known and well-reproducible, the $\mathrm{OH}$ concentration in the coflow region can be calculated and be used as a calibration source for the other image areas. A careful assessment of possible measurement errors has been performed in order to gain reliable data with corresponding uncertainties for the validation of numerical simulations. The $\mathrm{OH}$ concentrations were used to characterize the chemical state of the flame. The coflow exhibited a constant level of equilibrium $\mathrm{OH}$. Deviations from this level were indicative of chemical reactions of fuel and coflow oxygen or of mixing processes.

Measurements in a steady state lifted jet flame showed, based on probability density functions (PDFs) of the $\mathrm{OH}$ concentration that the flames seem to be stabilized by auto-ignition at the flame root. Further downstream, the OH PDFs became bimodal, which is indicative for flame stabilization by flame propagation.

The formation and growth of ignition kernels during transient fuel injection was also studied. It was shown that ignition kernels form at flow structures where low strain rates and low scalar dissipation rates are expected. Furthermore, ignition kernels form at very lean mixture fractions, where the highest mixture temperatures occur and where the chemical-kinetic ignition delay times are shortest. Subsequently, the flame kernel moves closer towards the jet core, i.e. to near-stoichiometric mixture fractions, where the laminar flame speed is highest.

Future work will focus on generating a validation data set for the current test case for numerical simulations, which will be publicly available. 


\section{Acknowledgements}

Portions of this work were presented at the OSA Imaging and Applied Optics Congress - Laser Applications to Chemical, Security and Environmental Analysis (LACSEA) in 2018, Paper \#2934647

\section{References}

1. T. C. Lieuwen, Unsteady combustor physics (Cambridge University Press, New York, 2012).

2. M. Stöhr, I. Boxx, C. Carter, and W. Meier, "Dynamics of lean blowout of a swirl-stabilized flame in a gas turbine model combustor," Proc. Combust. Inst. 33, 2953-2960 (2011).

3. C. M. Arndt, A. M. Steinberg, I. G. Boxx, W. Meier, C. D. Carter, and M. Aigner, "Flow-Field and Flame Dynammics of a Gas Turbine Model Combustor During Transition Between ThermoAcoustically Stable und Unstable States," in Proceedings of the ASME Turbo Expo, 2010), GT201022830.

4. K. Oberleithner, M. Stöhr, S. H. Im, C. M. Arndt, and A. M. Steinberg, "Formation and flame-induced suppression of the precessing vortex core in a swirl combustor: Experiments and linear stability analysis," Combust. Flame 162, 3100-3114 (2015).

5. E. Mastorakos, "Ignition of Turbulent Non-Premixed Flames," Prog. Energy Combust. Sci. 35, 57-97 (2009).

6. I. Boxx, C. M. Arndt, C. D. Carter, and W. Meier, "Highspeed Laser Diagnostics for the Study of Flame Dynamics in a Lean Premixed Gas Turbine Model Combustor," Exp. Fluids 52, 555-567 (2012).

7. O. Lammel, H. Schütz, G. Schmitz, R. Lückerath, M. Stöhr, B. Noll, M. Aigner, M. Hase, and W. Krebs, "FLOX ${ }^{\circledR}$ Combustion at High Power Density and High Flame Temperatures," J. Eng. Gas Turbines Power 132, 121503 (2010).

8. O. Lammel, M. Stöhr, P. Kutne, C. Dem, W. Meier, and M. Aigner, "Experimental Analysis of Confined Jet Flames by Laser Measurement Techniques," J. Eng. Gas Turbines Power 134, 041506 (2012).

9. F. Güthe, J. Hellat, and P. Flohr, "The Reheat Concept: The Proven Pathway to Ultralow Emissions and High Efficiency and Flexibility," J. Eng. Gas Turbines Power 131, 021503 (2009).

10. J. M. Fleck, P. Griebel, A. M. Steinberg, C. M. Arndt, and M. Aigner, "Auto-ignition and flame stabilization of hydrogen/natural gas/nitrogen jets in a vitiated cross-flow at elevated pressure," Int. J. Hydrogen Energy 38, 16441-16452 (2013).

11. J. M. Fleck, P. Griebel, A. M. Steinberg, C. M. Arndt, C. Naumann, and M. Aigner, "Autoignition of hydrogen/nitrogen jets in vitiated air crossflows at different pressures," Proc. Combust. Inst. 34, 3185 3192 (2013).

12. R. Cabra, T. Myhrvold, J. Y. Chen, R. W. Dibble, A. N. Karpetis, and R. S. Barlow, "Simultaneous Laser Raman-Rayleigh-LIF Measurements and Numerical Modeling Results of a Lifted Turbulent $\mathrm{H}_{2} / \mathrm{N}_{2}$ Jet Flame in a Vitiated Coflow," Proc. Combust. Inst. 29, 1881-1888 (2002).

13. B. B. Dally, A. N. Karpetis, and R. S. Barlow, "Structure of turbulent non-premixed jet flames in a diluted hot coflow," Proc. Combust. Inst. 29, 1147-1154 (2002).

14. P. R. Medwell, P. A. M. Kalt, and B. B. Dally, "Simultaneous imaging of OH, formaldehyde, and temperature of turbulent nonpremixed jet flames in a heated and diluted coflow," Combust. Flame 148, 48-61 (2007).

15. R. L. Gordon, A. R. Masri, S. B. Pope, and G. M. Goldin, "Transport budgets in turbulent lifted flames of methane autoigniting in a vitiated co-flow," Combust. Flame 151, 495-511 (2007).

16. B. C. Choi, K. N. Kim, and S. H. Chung, "Autoignited laminar lifted flames of propane in coflow jets with tribrachial edge and mild combustion," Combust. Flame 156, 396-404 (2009).

17. E. Oldenhof, M. J. Tummers, E. H. van Veen, and D. J. E. M. Roekaerts, "Ignition kernel formation and lift-off behaviour of jet-in-hot-coflow flames," Combust. Flame 157, 1167-1178 (2010).

18. P. R. Medwell and B. B. Dally, "Experimental Observation of Lifted Flames in a Heated and Diluted Coflow," Energy Fuels 26, 5519-5527 (2012).

19. C. M. Arndt, J. D. Gounder, W. Meier, and M. Aigner, "Auto-ignition and flame stabilization of pulsed methane jets in a hot vitiated coflow studied with high-speed laser and imaging techniques," Appl. Phys. B 108, 407-417 (2012).

20. F. Eitel, J. Pareja, D. Geyer, A. Johchi, F. Michel, W. Elsäßer, and A. Dreizler, "A novel plasma test rig for auto-ignition studies of turbulent non-premixed flows," Exp. Fluids 56, 186 (2015).

21. A. A. V. Perpignan, A. Gangoli Rao, and D. J. E. M. Roekaerts, "Flameless combustion and its potential towards gas turbines," Prog. Energy Combust. Sci. 69, 28-62 (2018).

22. R. L. Gordon, A. R. Masri, and E. Mastorakos, "Simultaneous Rayleigh temperature, $\mathrm{OH}-$ and $\mathrm{CH}_{2} \mathrm{O}-$ LIF imaging of methane jets in a vitiated coflow," Combust. Flame 155, 181-195 (2008).

23. P. R. Medwell, P. A. M. Kalt, and B. B. Dally, "Imaging of Diluted Turbulent Ethylene Flames Stabilized on a Jet in Hot Coflow (JHC) Burner," Combust. Flame 152, 100-113 (2008).

24. A. Dreizler and B. Böhm, "Advanced laser diagnostics for an improved understanding of premixed flame-wall interactions," Proc. Combust. Inst. 35, 37-64 (2015). 
25. V. Sick, "High speed imaging in fundamental and applied combustion research," Proc. Combust. Inst. 34, 3509-3530 (2013).

26. K. N. Gabet, N. Jiang, W. R. Lempert, and J. A. Sutton, "Demonstration of high-speed 1D Raman scattering line imaging," Appl. Phys. B 101, 1-5 (2010).

27. M. J. Papageorge, T. A. McManus, F. Fuest, and J. A. Sutton, "Recent advances in high-speed planar Rayleigh scattering in turbulent jets and flames: increased record lengths, acquisition rates, and image quality," Appl. Phys. B 115, 197-213 (2014).

28. T. A. McManus, M. J. Papageorge, F. Fuest, and J. A. Sutton, "Spatio-temporal characteristics of temperature fluctuations in turbulent non-premixed jet flames," Proc. Combust. Inst. 35, 1191-1198 (2015).

29. C. M. Arndt and W. Meier, "Quantitative OH Measurements in Turbulent Flames using LaserDiagnostics with High Spatio-Temporal Resolution," in OSA Imaging and Applied Optics Congress Laser Applications to Chemical, Security and Environmental Analysis, 2018), LTu2C.3.

30. M. J. Papageorge, C. Arndt, F. Fuest, W. Meier, and J. A. Sutton, "High-speed mixture fraction and temperature imaging of pulsed, turbulent fuel jets auto-igniting in high-temperature, vitiated co-flows," Exp. Fluids 55, 1763 (2014).

31. C. M. Arndt, M. J. Papageorge, F. Fuest, J. A. Sutton, W. Meier, and M. Aigner, "The role of temperature, mixture fraction, and scalar dissipation rate on transient methane injection and autoignition in a jet in hot coflow burner," Combust. Flame 167, 60-71 (2016).

32. C. M. Arndt, M. J. Papageorge, F. Fuest, J. A. Sutton, and W. Meier, "Experimental Investigation of the Auto-Ignition of a Transient Propane Jet-in-Hot-Coflow," Proc. Combust. Inst. (2018). DOI: 10.1016/j.proci.2018.06.195

33. C. M. Arndt, R. Schieß1, J. D. Gounder, W. Meier, and M. Aigner, "Flame stabilization and autoignition of pulsed methane jets in a hot coflow: Influence of temperature," Proc. Combust. Inst. 34, 1483-1490 (2013).

34. C. Morley, "Gaseq - A chemical Equilibrium Program for Windows. Version 0.79," (2005).

35. R. Sadanandan, W. Meier, and J. Heinze, "Experimental study of signal trapping of OH laser induced fluorescence and chemiluminescence in flames," Appl. Phys. B 106, 717-724 (2012).

36. A. Brockhinke, J. Krüger, M. Heusing, and M. Letzgus, "Measurement and simulation of rotationallyresolved chemiluminescence spectra in flames," Appl. Phys. B 107, 539-549 (2012).

37. K. C. Smyth and D. R. Crosley, "Applied Combustion Diagnostics," K.-H. Katharina and J. B. Jeffries, eds. (Taylor \& Francis, 2002), pp. 9-68.

38. J. Luque and D. R. Crosley, LIFBASE (version 2.1.1), SRI International, 1999.

39. M. Tamura, P. A. Berg, J. E. Harrington, J. Luque, J. B. Jeffries, G. P. Smith, and D. R. Crosley, "Collisional Quenching of $\mathrm{CH}(\mathrm{A})$, $\mathrm{OH}(\mathrm{A})$, and $\mathrm{NO}(\mathrm{A})$ in Low Pressure Hydrocarbon Flames," Combust. Flame 114, 502-514 (1998).

40. C. M. Arndt and W. Meier, "Influence of Boundary Conditions on the Flame Stabilization Mechanism and on Transient Auto-Ignition in the DLR Jet-in-Hot-Coflow Burner," Flow Turbul. Combust. (2018). DOI: $10.1007 / \mathrm{s} 10494-018-9991-6$

41. W. Meier, R. S. Barlow, Y.-L. Chen, and J.-Y. Chen, "Raman/Rayleigh/LIF measurements in a turbulent $\mathrm{CH} 4 / \mathrm{H} 2 / \mathrm{N} 2$ jet diffusion flame: experimental techniques and turbulence-chemistry interaction," Combust. Flame 123, 326-343 (2000).

42. C. Kortschik, S. Honnet, and N. Peters, "Influence of curvature on the onset of autoignition in a corrugated counterflow mixing field," Combust. Flame 142, 140-152 (2005).

43. G. Stahl and J. Warnatz, "Numerical investigation of time-dependent properties and extinction of strained methane- and propane-air flamelets," Combust. Flame 85, 285-299 (1991). 